\title{
INTERMITTENT CATHETERISATION WITH UNSTERILE INSTRUMENTS
}

\author{
By G. ZRUBeCky, M.D. \\ Rehabilitation Centre of the Allgemeinen Unfallversicherungsanstalt, \\ Tobelbad, Austria
}

REGARDING the problem of intermittent catheterisation, I would like to make a few comments. Guttmann (I966) has already published this method in 1949. In the recent literature (Bors, I967; Walsh, I968; Madersbacher, I972; Ott \& Rossier, I972) it is agreed that in the first phase of treatment of paraplegia intermittent catheterisation is the treatment of choice. Ott and Rossier (1972) report that at the Paraplegic Centre of Geneva intermittent catheterisation is performed by paramedical personnel.

Study trips of colleagues at English, Dutch and German centres have shown that, as in Switzerland and also in other countries, not only physicians are carrying out catheterisation, and that for this daily procedure not always the non-touch technique is followed. This highly sterile act of catheterisation with sterile gown, gloves, mask, etc. in 50 recent paraplegics three times daily really means: I 50 sterile pairs of gloves, I 50 sterile gowns, etc. - a gigantic expenditure of material, personnel and time. No clinic can really afford this expenditure, but nobody talks about it.

At present 30-40 new para- and tetraplegics are taken care of at the Rehabilitation Centre, Tobelbad. They are intermittently catheterised by the physicians under sterile conditions but without sterile gown. After 3-4 weeks the injured learn to catheterise themselves. This method is not original and new. Guttmann writes in the 'Handbuch der Neuro-Traumatologie' (I97I): 'In such cases (in the treatment of vesico-urethral reflux) we train the patient to change the catheter himself two to three times a week, observing the criterias of asepsis, which in many cases has proved to be more successful than the careless catheterisation by an orderly, nurse or physician, who is not well acquainted with the problems of paraplegics'.

Consciously the author has quoted Guttmann word by word. These statements cannot only be agreed upon entirely, but can be proved by experiences with II 4 paraplegics. Our injured are trained to catheterise themselves in bed, in the wheelchair and also in a car without help.

Every patient has a small bag containing disposable catheter, urinal, a pair of forceps, scissors and lubricant. By means of this equipment the danger of hospitalisation is less and simpler to prevent than if the catheterisation is carried out by a physician, wearing a sterile gown-but worn all the way through the ward when he does the catheterisation. This small bag can be taken along everywhere. Thus our injured are entirely independent in micturition during their daily life. With this method of intermittent catheterisation we have achieved a sterile urine in $77 \cdot 2$ per cent. of I I 4 paraplegics in the time between May I97I and April 1972. Insignificant better results are reported by Rossier (1972) 88 per cent. in 42 patients; Walsh (1968) 83 per cent. in 107 paraplegics. While there is agreement 
about intermittent catheterisation as the treatment of choice at the start of treatment in paraplegics there is, however, no accordance to how long intermittent catheterisation should be carried out.

In the course of intermittent catheterisation, at least a bladder automatism develops. But this leads to the problem of defining the case and quality of function of bladder automatism. In most cases the following definition may serve as a standard:

\section{Continence.}

2. Sterile urine.

Doubtless there is a direct relation between infection, residual urine, stones, etc. and continence, for infection and incontinence result from each other. Only when the two conditions are realised-continence and sterile urine-is bladder training successful.

Many paraplegics do not succeed at all or only in a very unsatisfactory way in achieving a bladder automatism, satisfying the physician and the injured as well. Bors (1967) reports that 28 of 36 patients ( 77 per cent. and Madersbacher (I972) that 18 of 23 patients could be discharged without regular catheterisation. From January I97I to April I972 I42 paraplegics were admitted (mainly recently injured persons) at Tobelbad. In 37 of these cases ( 26 per cent.) a satisfactory bladder automatism was not managed. For about one-fourth of all paraplegicsthis number corresponds to the data of Bors (1967) and Madersbacher (1972)-it is not possible to get a satisfactory bladder automatism.

\section{How shall the Urological Treatment be carried on in this Group of Patients?}

(a) Incontinent Contracted Bladder. Bladder-neck-resection is the only possibility. However, it is unsatisfactory for the patient because he has to wear a urinal thereafter.

(b) Incontinence with sufficient bladder capacity arouses the question: Indwelling catheter or permanent intermittent catheterisation? The dangers of an indwelling catheter are known. Therefore, this method with exceptions, has to be refused. Certainly the possibility of permanent regular intermittent catheterisation is better than an unsuccessful bladder training. So far it has not generally been carried out because of mere technical reasons (sterility during catheterisation at home, sterility of catheter and necessary instruments). Only because of these mere technical reasons many paraplegics were finally supplied with an indwelling catheter. The responsibility of changing the catheter could easily be carried over to the family physician. Surely this is the simplest but also the most unsatisfactory solution.

Now, every paraplegic and also all low tetraplegics are able to carry out regular and sterile intermittent catheterisation themselves, after being discharged from hospital, by means of applying the sterile disposable catheter without instrument and urinal. Thereby, the patient is continent and independent at home as well as in business.

It has been pointed out that the method of intermittent catheterisation can also be considered as a final answer to emptying the bladder if-with permanent incontinence but sufficient bladder capacity-the bladder training has proved to be unsuccessful. But in this instance we have to ask: For how long can intermit- 
tent catheterisation be carried out? In literature there are only scarce data. Bors (1967) recommends intermittent catheterisation of up to 3 months; Ott and Rossier (I972) on an average of 50 days and Madersbacher (I972) for up to 30 weeks.

A survey of 43 paraplegics already able to perform regular intermittent catheterisation for about I-2 years was performed. I personally know an injured, who has emptied his bladder by regular intermittent catheterisation for more than 8 years, and he is continent. Experienced urologists, like Legner (I97I) and others, state that patients can intermittently catheterise themselves for an unlimited period of time. That such patients tolerate bacteria in their bladder almost physiologically and the rate of infection is rather low against expectations, while virulent organisms lead to severe infections in hospital.

\section{REFERENCES}

Bors, E. (1967). Urol. int. 236-249.

GuttMann, L. (1949). Br. Surg. Pract. 6, 445.

Guttmann, L. \& Frankel, H. (1966). Int. F. Paraplegia, 4.

Kessel, F. K., GuttMann, L., MAURER G. (I97I). Neuro-Traumatologie mit Einschlu $\beta$ der Grenzgebiete. II. Band, Urban \& Schwarzenberg, München-Berlin-Wien.

LEGNER, CH. (I97I). Medical Tribune, April 8th, I97I.

MADERSBACHER, H. (1972). Actuelle Urologie, 4, 83-85.

OtT, R. \& Rossier, A. B. (I972). Actuelle Urologie, 4, 79-82.

WALSH, J. J. (1968). Int. F. Paraplegia, 6.

\section{Discussion}

In the ensuing discussion in which Doctors Michaelis, Dollfus and Sir Ludwig Guttmann took part, criticism was expressed to Dr. Zrubecky's paper.

This criticism was particularly directed towards the film shown by him to demonstrate self-catheterisation by a chronic paralysed patient without applying proper precautionary technique. The fact that his man and a few others of this type got away without serious ascending infection of the urinary tract does not prove anything, having regard to the many others who do great damage to themselves by such careless method. This film can only do harm by encouraging other people-both doctors and patientsto abandon the strict precautions in catheterisation which are so vital to prevent serious infection of the urinary tract. Moreover, Dr. Zrubecky's statement that TUR is the only possibilty in the treatment of incontinence of the contracted bladder will certainly be unacceptable to everyone with experience in this matter. While the dangers of permanent indwelling catheter in producing various complications is now generally accepted, the danger of incompetent intermittent catheterisation is at least as great, whether this applies to the initial or later stages of spinal paraplegia and tetraplegia. 